\title{
Does Bitter Melon (Momordica charantia) have Antibacterial Property?
}

\section{Debolina Ghosh*}

High School Student, Hathaway Brown School, Shaker Heights, Ohio, USA

\begin{abstract}
Introduction: The aim of this study was to see if Mormodica charantia, better known as bitter melon had any antibacterial property as claimed by many food and nutrition specialists.

Materials and Methods: Bitter melon extract was obtained from its interior, middle, and outside skin and mixed with sterile distilled water. Agar gel disk diffusion method was used to look for clear zones of inhibition of the Staphylococcus aureus (S. aureus) and Escherichia coli (E. coli) colonies around the disks soaked with bitter melon extracts. Standardized Penicillin and Erythromycin disks were used as positive control for S. aureus while Gentamicin disks were used for $E$. coli. Unmedicated disks soaked with distilled water were used as negative control. Petri dishes with bacteria and the disks were incubated at $37^{\circ} \mathrm{C}$. After 24 hours, the clear zones of inhibition around the disks were measured. In addition, liquid extract of bitter melon was put in liquid microKwik culture vials containing S. aureus and E. coli. These were incubated at $37^{\circ} \mathrm{C}$ for 24 hours and observed for any color change.
\end{abstract}

Results: After 24 hours of incubation, petri dishes containing S. aureus with Penicillin and Erythromycin disks showed clear zones of inhibition (average $12.9 \mathrm{~mm}$, and $9 \mathrm{~mm}$ respectively). This was similar to the Gentamicin disks for $E$. coli (average 11 $\mathrm{mm}$ ). There were no clear zones of inhibition around the unmedicated disks or the ones soaked in distilled water or bitter melon extract (interior, middle or exterior skin). Bitter melon extract did not change the color of liquid microKwik media containing the bacteria.

Discussion/Conclusions: Contrary to common belief bitter melon does not have any antibiotic property. Though this study drew a negative conclusion, the inference has significant implication in the field of food technology, nutrition and alternative/herbal medicine.

Keywords: Bitter melon; Antibiotic; S. aureus; E. coli; Penicillin; Erythromycin; Gentamicin; Zone of inhibition

\section{Introduction}

Infection is a process in which organisms such as bacteria, viruses, or fungi invade body tissues and produce inflammation and tissue damage [1]. Symptoms of infection depend on the part of the body affected and range from fever, cough, vomiting, diarrhea, fatigue, headache, altered consciousness and myriad of others. Infections can be localized, when they are contained in one part of the body or systemic, when they spread to the whole body via the bloodstream [2]. Bacteria and viruses are the most common cause of infection. In general, bacteria cause more severe infection than viruses. Bacteria are single-celled organisms that can live independently and invade body tissues. Viruses, on the other hand, cannot exist by themselves. They thrive on living human cells while invading the human body [3].

Bacteria are Gram positive or negative based on their staining properties after using Gram's stain; bacteria which take up the stain looking blue/purple are called Gram positive and the ones which remain unstained are called Gram negative. This staining characteristic is based on the thickness and physico-chemical properties of the bacterial cell wall. In Gram positive bacteria the cell wall is thick and $50-90 \%$ of it is composed of peptidoglycan. In Gram negative bacteria it is thin and only $10 \%$ is composed of peptidoglycan. Gram positivity or negativity of bacteria, determine their susceptibility to specific antibiotics. This information is vital when selecting antibiotics to treat human infections [4].

One of the most common infection-causing Gram positive bacteria is Staphylococcus aureus (S. aureus). Staphylococci can cause minor infections like boils on the skin or major illnesses like pneumonia and meningitis. It is most often found on the skin, in nasal passages, or around soft tissues. Newborn babies, individuals with diabetes or cancer, or those with a weak immune system are most prone to getting staphylococcal infections. These infections maybe transmitted through direct contact or through blood to different organs, for example, to the heart to cause endocarditis. Staphylococcal sepsis or bacteremia is not uncommon. Untreated staphylococcal sepsis has a very high mortality rate of up to $80 \%[5,6]$.

Escherichia coli (E. coli) are a prototype of Gram negative bacteria. It causes human infections primarily affecting the gastrointestinal system with frequent systemic spread. It can cause septicemia, meningitis and brain abscess. The mortality from $E$. coli septicemia may reach $30-50 \%$ [7].

Infections are treated with antibiotics. Antibiotics can either be bacteriostatic or bactericidal, meaning they either prevent the bacteria from growing or kill them [8]. Antibiotics like Penicillin, which attack cell walls/ membranes, or those that impair functioning of bacterial enzymes, like Rifamycins, are usually bactericidal $[9,10]$. Bacteriostatic agents inhibit the active growth of bacteria without killing the microorganism. They either reduce bacterial protein synthesis or inhibit DNA replication. Erythromycin, a macrolide antibiotic is

${ }^{*}$ Corresponding author: Debolina Ghosh, Hathaway Brown School, 19600 North Park Blvd, Shaker Heights, Ohio- 44122, USA, Tel: 440-349-3678; E-mail: Ighosh17@hb.edu

Received March 06, 2014; Accepted July 17, 2014; Published July 31, 2014

Citation: Ghosh D (2014) Does Bitter Melon (Momordica charantia) have Antibacterial Property? J Food Process Technol 5: 345. doi:10.4172/2157 7110.1000345

Copyright: (C) 2014 Ghosh D. This is an open-access article distributed under the terms of the Creative Commons Attribution License, which permits unrestricted use, distribution, and reproduction in any medium, provided the original author and source are credited. 
a classic example of a bacteriostatic antibiotic. Both penicillin and erythromycin primarily work on the Gram positive bacteria [11]. Gram negative bacteria are treated by agents like aminoglycosides which work on the bacterial cell membrane and are bactericidal $[9,11]$. Aminoglycosides can also have bacteriostatic property through their effect on 30s ribosome preventing protein synthesis. Gentamicin is the prototype aminoglycoside used in clinical practice $[12,13]$.

For the purpose of this experiment, S. aureus was chosen as the Gram positive and E. coli as the Gram negative bacteria. For treating staphylococcal infections, antibiotics such as Cephalosporins and Nafcillin (a form of Penicillin) are used. Penicillin, a bactericidal agent, destroys the bacteria by breaking the cell wall of the organism. Bacteria constantly rebuild their cell walls by a process called peptidoglycan synthesis. Penicillin is able to inhibit this process by inactivating an enzyme called transpeptidase which is essential for the "cross-linking" between the inner and outer membrane walls of the bacteria. Without this link, the cell wall breaks leading to death of the bacteria. Beta-lactam is the core moiety of Penicillin which is responsible for this action $[8,9]$. Erythromycin is a macrolide antibiotic which works as bacteriostatic on Gram positive bacteria. E. coli had been chosen in this experiment as a prototype of Gram negative bacteria. Gentamicin works both as a bactericidal and as a bacteriostatic agent against E. coli [8,11-13].

Bitter Melon or Momordica charantia, is a popular vegetable in southern Asia. It is mainly used for culinary purposes, but it has been claimed to work against diabetes, cancer, and cardiovascular diseases. There may be a particular enzyme or insulin like substance within it that is responsible for regulating the body metabolism and transporting glucose from blood into the cells $[14,15]$. Also in parts of Africa, it has been used as a treatment for gastrointestinal parasitic disease [16,17]. Anecdotal studies have concluded that bitter melon may have antimalarial and antiviral properties. The exact property of this vegetable that makes it so beneficial for health is not known [1820]. Though many benefits have been claimed including its apparent antibacterial property, there is no systematic study to prove whether bitter melon has antibacterial property or not [18]. Bitter melon contains glycosides, terpenoids, and momordicin-1 which could be responsible for its "medicinal properties" [21-23]. Momordicin inhibits the production of ribosomal proteins. One is tempted to postulate that this inhibition of protein may make bitter melon bacteriostatic. Aminoglycoside antibiotics like gentamicin inhibit protein synthesis in Gram negative bacteria through their inhibitory action on 30s ribosomal RNA. Without this protein the bacteria die [23]. This could also be true for bitter melon which has a chemical substance with similar function $[8,12,13]$. Thus one may hypothesize that bitter melon may work as an antibacterial agent against Gram negative organisms just like aminoglycosides.

Some precautions must be taken before consuming bitter melon because it contains vicine, which may trigger favism in susceptible individuals. The red seeds of bitter melon may be potential choking hazards, more so in young children [24].

With the above background, this study was undertaken with the following goals: 1) to prove or disprove the hypothesis that bitter melon has some antibacterial property, 2) if it has antibacterial property, whether the effect is on Gram positive (S. aureus) and/or Gram negative (E. coli) bacteria, 3) to know whether the antibacterial effect is through bactericidal or bacteriostatic mechanism.

\section{Materials and Methods}

Disk diffusion technique was used to assay the antibiotic efficacy of bitter melon extract, prepared after mixing with sterile distilled water [25]. The clear zone of inhibition of the bacterial colonies around the disk containing the extract on the nutrient agar media plate was the criterion for the antibiotic action. Comparison was done using commercially available standardized disks containing Penicillin, Erythromycin and Gentamicin as the active (positive) control. Distilled water soaked disks and plain non-medicated disks were used as the inactive (negative) control. In addition, bitter melon extract was mixed with the commercially available standard microKwik culture vials containing S. aureus and E. coli in liquid broth. Any color change of the solution after 24 hours of incubation at $37^{\circ} \mathrm{C}$ was observed.

Bitter melon was divided into three parts, interior, middle part of the skin, and exterior skin, which were then formed into liquid extracts after homogenization and mixing with sterile distilled water. Unprepared disks were soaked in these solutions and put on petri dishes containing nutrient agar culture media smeared with colonies of Staphylococcus aureus (S. aureus) and Escherichia coli (E. coli). A similar procedure was followed with the un-medicated and distilled water soaked disks which acted as negative control. Positive (active) controls were obtained by using commercially available standardized Penicillin and Erythromycin disks put in the petri dishes containing S. aureus to compare action against Gram positive organism. Similarly Gentamicin disks were put in the petri dishes containing E. coli as positive (active) control for action against Gram negative organism. The aforementioned petri dishes were then incubated at a temperature of $37^{\circ} \mathrm{C}$. After 24 hours the clear zones of inhibition around the disks were measured. In addition the liquid extract of bitter melon was put in the commercially available liquid microKwik culture vial containing $\mathrm{S}$. aureus and E. coli, incubated for 24 hours, and observed for any change in color (yellow or white) of the media. The same experiments were repeated for reliability of the study.

\section{Results}

Table 1 shows zones of inhibition of growth of S. aureus, manifested as clear area around the disks- a) non-medicated plain, b) impregnated with distilled water, c) impregnated with bitter melon extracts from interior core, middle part of the skin and external skin, d) penicillin and e) erythromycin, after 24 hours of incubation. The average zone of inhibition with Penicillin disk was $12.9 \mathrm{~mm}$ (range 12-15 mm). The average zone of inhibition with Erythromycin disk was $9 \mathrm{~mm}$ (range 6-11 mm). There was no clear zone of inhibition around the unmedicated disks or around the disks soaked with bitter melon extract or distilled water.

Table 2 shows the zones of inhibition of growth of E. coli manifested as clear area around the disks- a) non-medicated plain, b) impregnated with distilled water, c) impregnated with bitter melon extracts from inner core, middle part of the skin and external skin, and d) gentamicin, after 24 hours of incubation. The average zone of inhibition around gentamicin disk was $11 \mathrm{~mm}$ (range 6-15 mm). There was no clear zone of inhibition around the un-medicated disk or the disks soaked with bitter melon extracts or distilled water.

Figure $1 \mathrm{a}$ and $1 \mathrm{~b}$ show clear zones of inhibition of S. aureus colonies around Penicillin (Figure 1a) and Erythromycin (Figure 1b) disks, whereas Figures 1c, 1d and 1e show lack of any clear zone of inhibition around the disks containing bitter melon extract from outer skin, middle part of the skin and inner core. Figure 2 a shows clear zone of inhibition of $E$. coli colonies around the Gentamicin disks, whereas Figures $2 b, 2 c$ and $2 d$ ) show lack of any clear zone of inhibition around the disks containing bitter melon extracts. 
Citation: Ghosh D (2014) Does Bitter Melon (Momordica charantia) have Antibacterial Property? J Food Process Technol 5: 345. doi:10.4172/21577110.1000345

Page 3 of 5

\begin{tabular}{|c|c|c|c|c|c|}
\hline Independent Variables & \multicolumn{3}{|c|}{ Zone of Inhibition (mm) } \\
\hline & Disk 1 & Disk 2 & Disk 3 & Disk 4 \\
\hline Control 1 & 0 & 0 & 0 & 0 \\
\hline Control 2 & 0 & 0 & 0 & 0 \\
\hline Distilled Water 1 & 0 & 0 & 0 & 0 \\
\hline Distilled Water 2 & 0 & 0 & 0 & 0 \\
\hline Interior Skin 1 & 0 & 0 & 0 & 0 \\
\hline Interior Skin 2 & 0 & 0 & 0 & 0 \\
\hline Middle Skin 1 & 0 & 0 & 0 & 0 \\
\hline Middle Skin 2 & 0 & 0 & 0 & 0 \\
\hline Exterior Skin 1 & 0 & 0 & 0 & 0 \\
\hline Exterior Skin 2 & 0 & 0 & 0 & 0 \\
\hline Penicillin 1 & 13 & 12 & 0 & 0 \\
\hline Penicillin 2 & 12 & 12 & 0 \\
\hline Erythromycin 1 & 11 & 15 & 0 \\
\hline Erythromycin 2 & 7 & 10 & 0 \\
\hline
\end{tabular}

Table 1: Zones of Inhibition of Staphylococcus aureus around the un-medicated (control 1 \& 2), distilled water soaked, bitter melon extract soaked, Penicillin and Erythromycin disks, after 24 hours of incubation at 37 degree $C$ (series of 2 experiments).

\begin{tabular}{|c|c|c|c|c|c|}
\hline Independent Variables & \multicolumn{4}{|c|}{ Zone of Inhibition (mm) } \\
\hline & Disk 1 & Disk 2 & Disk 3 & Disk 4 & Disk 5 \\
\hline Control 1 & 0 & 0 & 0 & 0 \\
\hline Control 2 & 0 & 0 & 0 & 0 \\
\hline Distilled Water 1 & 0 & 0 & 0 & 0 \\
\hline Distilled Water 2 & 0 & 0 & 0 & 0 \\
\hline Interior Skin 1 & 0 & 0 & 0 & 0 \\
\hline Interior Skin 2 & 0 & 0 & 0 & 0 \\
\hline Middle Skin 1 & 0 & 0 & 0 & 0 \\
\hline Middle Skin 2 & 0 & 0 & 0 & 0 \\
\hline Exterior Skin 1 & 0 & 0 & 0 & 0 \\
\hline Exterior Skin 2 & 0 & 0 & 0 & 0 \\
\hline Gentamicin 1 & 8 & 7 & 0 & 0 \\
\hline Gentamicin 2 & 12 & 15 & 0 & 0 \\
\hline
\end{tabular}

Table 2: Zones of Inhibition of Escherichia coli around the un-medicated (control 1 \& 2), distilled water soaked, bitter melon extract soaked, and Gentamicin disks, observed after 24 hours of incubation at 37 degree $C$ (series of 2 experiments).

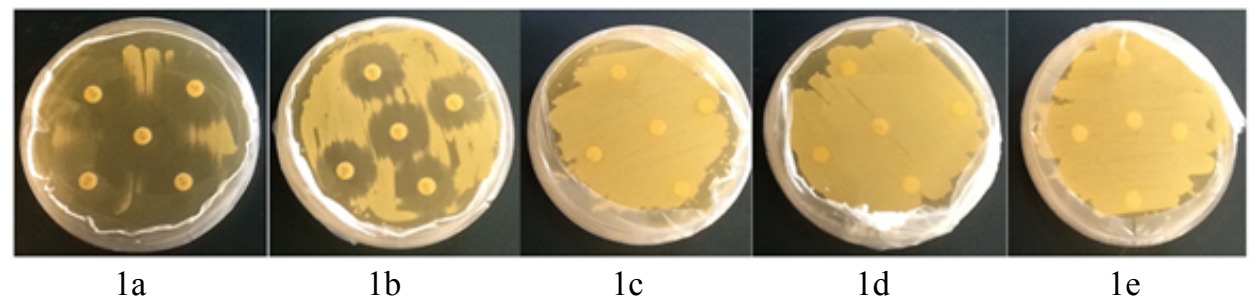

$1 \mathrm{a}$

$1 \mathrm{~b}$

$1 \mathrm{~d}$

$1 \mathrm{e}$

Figure 1: This shows clear zones of inhibition around the Penicillin (1a) and Erythromycin (1b) disks. There was no clear zone of inhibition around the disks containing bitter melon extract from outer skin (1c), middle part of the skin (1d) and inner core (1e). Background looks yellow due to the growth of the Staphylococcal aureus colonies.

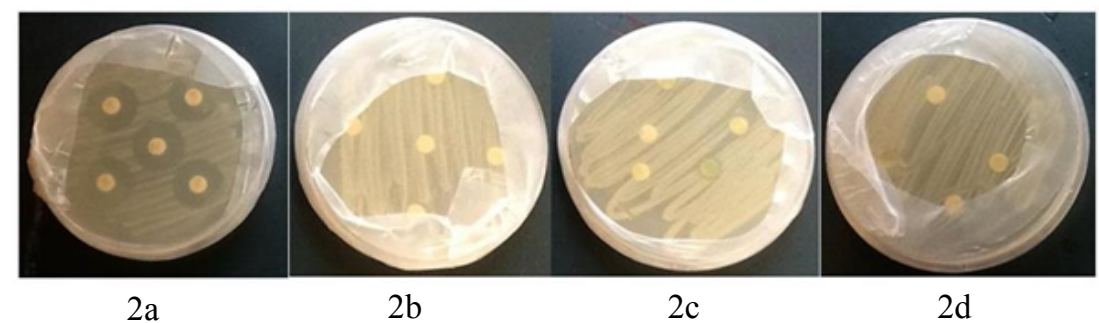

Figure 2: This shows clear zone of inhibition around Gentamicin disks (2a), but no clear zone of inhibition around the disks containing bitter melon extract from outer skin (2b), middle part of the skin (2c) and inner core (2d). Background looks white due to Eschericia coli colony growth. 
There was no change in the color of the liquid microKwik culture media containing the bacteria (yellow for S. aureus and white for $E$. coli) after 24 hour incubation following treatment with bitter melon extracts.

\section{Discussion}

This is the first study that has proved that bitter melon (Momordica charantia) does not have any antibiotic properties, either bacteriostatic or bactericidal, when tested against $\mathrm{S}$. aureus, Gram positive bacteria, and E. coli, Gram negative bacteria. The exterior skin, middle part of the skin, and interior core of the vegetable were tested separately to show whether any part of the vegetable contained antibiotic property. None of these extracts was effective in preventing the growth of the bacteria. This study nullifies the erroneous perception held by some nutritionists and believers of alternative medicine that eating bitter melon prevents and treats infections in humans.

For the purpose of reproducibility of the data, this study did repeat a second set of experiments following the same methodology. Both sets of data were comparable (Tables 1 and 2) proving the reliability of the data. The antibiotic efficacy was compared with Penicillin, a bactericidal agent and Erythromycin, a bacteriostatic agent, both effective against $\mathrm{S}$. aureus. Similarly Gentamicin disks were used for comparison against E. coli. This study used the principle of agar gel disk diffusion technique inhibiting bacterial growth in the culture media producing clear zones of inhibition around the disks containing the medications, the extracts, distilled water, as well as those which were un-medicated. This is a standard method used in the laboratory to determine antibiotic efficacy. As the $S$. aureus colonies look golden, and E. coli white, it is very easy to find the exact zone of inhibition of bacterial growth by the presence of clear area around the disks with a yellow or white background of the surface of the culture media (Figures 1 and 2). As expected, S. aureus growth in the culture media was inhibited by both Penicillin and Erythromycin (more by penicillin). This testifies the fact that bactericidal agents like Penicillin are more potent than bacteriostatic agents like Erythromycin for treating infection by Gram positive organisms. Similarly Gentamicin was very effective against Gram negative bacteria, E. coli $[10,11,13]$. To make the interpretation of this study more objective a negative control arm with distilled water and plain un-medicated disks was used.

This study also attempted to assess the mechanism of action of the bitter melon extract in infection, whether bactericidal or bacteriostatic. For this information the extract was mixed with the liquid microKwik culture vial containing S. aureus and E. coli and then incubated for 24 hours to note any color change of the media. The bactericidal mechanism is proven if yellow or white color of the media becomes fainter, implying the bacteria are being killed rather than inhibited due to bacteriostatic action. Absence of any color change of the liquid media proves that there is no bactericidal action of the bitter melon.

\section{Limitations of the Study}

Disk diffusion method for antibiotic efficacy has some limitations, though in general this method is the most commonly used in clinical practice. From this study one cannot completely rule out the possibility of bitter melon having mild antibacterial property which was not detected in a crude extract. The concentrated extract may demonstrate some antibiotic efficacy. This study has not tested other health benefits bitter melon may have in humans.

\section{Summary/Conclusion}

This study aimed to prove or disprove antibiotic property of bitter melon, which has been postulated without a scientific proof. There were no zones of inhibition of the Staphylococcal aureus or Escherichia coli colonies around the disks impregnated with bitter melon extracts compared to those standard Penicillin, Erythromycin, and Gentamicin disks. Similarly there was no effect in the liquid microKwik culture vials after mixing with the bitter melon extract, thereby again disproving its bactericidal action. This experiment demonstrated that the bitter melon did not have an antibacterial property, either against Gram positive or Gram negative bacteria. The conclusions of this study disprove the notion carried by many food and nutrition specialists that bitter melon has antibiotic property when consumed by humans. Even though bitter melon may not have antibacterial activity, this study does not disprove other health benefits this vegetable may have.

\section{Acknowledgement}

This study was conducted at the Biology Laboratory, Hathaway Brown School Shaker Heights, Ohio, USA. I must thank the help provided by Debabrata Ghosh $M D$ in conducting this study and during preparation of the manuscript.

Study sponsorship or funding

The author did not receive any financial support for the research and/or the authorship of this article.

Disclosure of Author's Financial Relationships

The author reports no disclosure.

\section{References}

1. Signore A (2013) About inflammation and infection. EJNMMI Res 3: 1-8

2. Lawson EH, Hall BL, Ko CY (2013) Risk factors for superficial vs. deep/organspace surgical site infections: implications for quality improvement initiatives. JAMA Surg 148: 849-858.

3. Van Ooij C (2011) Immunology: virus and bacterium gang up on host. Nature Reviews Microbiology 9: 559.

4. Cerny C (1976) Method for the distinction of Gram negative from Gram positive bacteria. Eur J Appl Microb Biotechnology 3: 223-225.

5. Conterno LO, Wey SB, Castelo A (1998) Risk factors for mortality in Staphylococcus aureus bacteremia. Infection Control \& Hospital Epidemiolgy 19: 32-37.

6. Van Hal SJ, Jensen SO, Vaska VL, Espedido BA, Paterson DL, et al. (2012) Predictors of mortality in Staphylococcus aureus bacteremia. Clin Microb Rev 25: 362-385.

7. Kim Yun-K, Pai H, Lee H-J, Park S-E, Choi E-H, et al. (2002) Bloodstream Infections by Extended-Spectrum lactamase-Producing Escherichia col and Klebsiella pneumonia in Children: Epidemiology and Clinical Outcome. Antimicrob Agents Chemoth 46: 1481-1491.

8. Pankey GA, Sabath LD (2004) Clinical Relevance of Bacteriostatic versus Bactericidal Mechanism of Action in the Treatment of Gram-Positive Bacterial Infections. Clin Inf Dis 38: 864-870.

9. Lederberg J (1957) Mechanism of action of Penicillin. J Bacteriol 73: 144.

10. Arioli V, Berti M, Carniti G, Randisi E, Rossi E, et al. (1981) Antibacterial activity of DL 473, a new semisynthetic rifamycin derivative 34: 1026-1032.

11. Stassi DL, Kakavas SJ, Reynolds KA, Gunawardana G, Swanson S, et al. (1998) Ethyl-substituted erythromycin derivatives produced by directed metabolic engineering. Proc Natl Acad Sci 95: 7305-7309.

12. Yoshizawa S, Fourmy D, Pugilisis JD (1998) Structural origins of gentamicin antibiotic action. The EMBO Jl 22: 6437-6448.

13. Bizzarro MJ, Dembry LM, Baltimore RS, Gallagher PG (2008) Changing Patterns in Neonatal Escherichia coli Sepsis and Ampicillin Resistance in the Era of Intrapartum Antibiotic Prophylaxis. Pediatrics; 121: 689-696.

14. Basch WE, Gabardi S, Ulbricht C (2003) Bitter melon (Momordica Charantia): a review of efficacy and safety. Am J Health-Syst Pharm 60: 356-359.

15. Ray RB, Raychoudhuri A, Steele R, Nerukar P (2010) Bitter Melon (Momordica Charantia) Extract Inhibits Breast Cancer Cell Proliferation by Modulating Cell Cycle Regulatory Genes and Promoted Apoptosis. Cancer Res 70: 1925-1931. 
Citation: Ghosh D (2014) Does Bitter Melon (Momordica charantia) have Antibacterial Property? J Food Process Technol 5: 345. doi:10.4172/21577110.1000345

16. Day C, Cartwright T, Provost J (1990) Hypoglycemic effect of Momordica Charantia extracts, Planta Med 56: 426-429.

17. Sarkar S, Pranava M, Marita R (1996) Demonstration of the hypoglycemic action of Momordica Charantia in a validated animal model of diabetes. Pharmacol Res 33: 1-4.

18. Grover JK, Yadav SP (2004) Pharmacological actions and potential uses of Momordica Charantia: A review. J Ethnopharmacol 93:123-132.

19. Bouribaiar AS, Lee-Huang S (1996) The activity of plant-derived antiretroviral proteins MAP 30 and GAP31 against herpes simplex virus in vitro. Biochem. Biophys Res Commun 219: 923-929.

20. Lee-Huang S, Huang PL, Chen HC, Huang PL, Bourinbaiar A, et al. (1995) Anti-HIVE and anti-tumor activities of recombinant MAP30 from bitter melon. Gene 161:151-156.
21. Nhiem NX, Kiem PV, Minh CV, Ban NK, Cuong NX, et al. (2010) AlphaGlucosidase inhibition properties of cucurbitane-type triterpene glycosides from the fruits of Momordica Charantia. Chem Pharm Bull 58: 720-724.

22. Ma J, Whittaker P, Keller AC, Mazzola EP, Pawar RS, et al. (2010) Cucurbitanetype triterpenoids from Momordica Charantia. Planta Med 76: 1758-1761.

23. Sasa M, Inoue I, Shinoda Y, Takahashi S, Seo M, et al. (2009) Activating Effect of Momordin, Extract of Bitter Melon (Momordica Charantia L.), on the Promoter of Human PPARdelta. J Atheroscler Thromb 16: 888-892.

24. Dutta PK, Chakravarty AK, Chowdhury US (1981) Vicine, a favism-inducing toxin from Momordica Charantia Linn. seeds. Indian J Chem 20B: 669-671.

25. Driscoll AJ, Bhat N, Karon RA, O'Brien KL, Murdoch DR (2012) Disc Diffusion Bioassays for the Detection of Antibiotic Activity in Body Fluids: Applications for the Pneumonia Etiology Research for Child Health Project. Clin Inf Dis 54 (Suppl 2): S159-S164. 